\title{
Effect of Laboratory Synthesized Cu-Chitosan Nanocomposites on Control of PFSR Disease of Maize caused by Fusarium verticillioids
}

\author{
Manju Kumari Choudhary ${ }^{1 *}$, Arunabh Joshi ${ }^{1}$, S.S. Sharma ${ }^{2}$ and Vinod Saharan ${ }^{1}$ \\ ${ }^{1}$ Department of Molecular Biology and Biotechnology, ${ }^{2}$ Department of Plant Pathology, \\ Rajasthan College of Agriculture, Maharana Pratap University of Agriculture and Technology, \\ Udaipur, Rajasthan, India \\ *Corresponding author
}

\section{A B S T R A C T}

\section{Keywords}

Cu-chitosan, Fungal disease, PFSR, Maize, Nanocomposites.

Article Info

Accepted:

19 June 2017

Available Online:

10 August 2017
The purpose of this study was to evaluate $\mathrm{Cu}$-chitosan NCPs for its antifungal activities against Fusarium verticillioids causing post flowering stalk rot (PFSR) disease of maize. Cu-chitosan NCPs were prepared based on the ionic gelation of chitosan with tripolyphosphate anions and Copper ions having particle size $(295.4 \mathrm{~nm})$, polydispersity index $(0.28)$, zeta potential $(+19.6 \mathrm{mV})$.Various concentrations of $\mathrm{Cu}$-chitosan NCP was applied in pot and field experiments.Cu-chitosan NCPs at the concentration of $0.1 \%$ and $0.14 \%$ found effective in controlling PFSR in pot experiments. In Surya local (4 hrs treated seeds) PEDC was $48.1 \%$ at $0.1 \%$ Cu-chitosan NCP. In Surya local ( 8 hrs treated seeds) $49.6 \%$ PEDC was observed at 0.1 and $0.14 \% \mathrm{Cu}$-chitosan NCPs. In field experiments, $\mathrm{Cu}-$ chitosan NCP at the concentration of $0.06 \%$ found effective in controlling PFSR disease. Significant disease control of PFSR was observed (33.9\%) at $0.06 \%$ Cu-chitosan NCPs in Surya local (4 hrs treated seeds). All together Cu-chitosan NCPs have remarkable potential and act as an effective antifungal agent against PFSR of maize in pot condition as well as in field condition for crop protection.

\section{Introduction}

Maize (Zea mays L.) is one of the highly demanding crops for food, livestock feed and energy sector. It is one of the most adaptable crop in diverse environment and third most important cereal crop after wheat and rice (Cassman et al., 2003; Cassman and Liska, 2007 Grassini et al., 2011). It is a unique crop due to its elevated yield potentiality, multipurpose use low cost per unit of production and grown throughout the year because of its photo-insensitiveness (Rashid, 2009). In India, it is cultivated over an area of 9.23 million ha and production is about 23.67 million tonnes with average productivity of
$2564 \mathrm{~kg} / \mathrm{ha}$ (Anonymous, 2015a). Area under maize cultivation in Rajasthan is about 0.89 million ha with the production of 1.55 million tonnes grain, achieving a productivity of 1740 $\mathrm{kg} / \mathrm{ha}$ (Anonymous, 2015b).

Sustainability in maize production is incessantly confronted by diseases that cause quantitative and qualitative losses. Post flowering stalk rot (PFSR) is one of the destructive and widespread diseases of commercially grown cultivars of maize. This disease is difficult to characterize because of the complex nature of infectious pathogens 
namely Fusarium spp., Macrophomina phaseolina and Cephalosporium maydis. The disease is prevailing in most of the maize growing areas of north to south states of India (Shekhar et al., 2010). The pathogens commonly affect the roots crown regions and lower internodes. Because of the rot stalk supply of water and nutrients gets interrupted resulting in plants with poorly filled kernels and finally stalk lodge. The disease incidence recorded in India ranged from 10 to $70 \%$ (Rathore et al., 2005; Shekhar et al., 2010).

Fungicides have been applied by soil, seed and foliar means with substantial success to control fungal diseases of maize (Rodriguez et al., 2011). The usage of highly toxic chemicals for control of plant diseases has increased exponentially to achieve higher productivity in general and maize in particular. The excessive use of toxic chemicals has lead to the deposition of nondegradable chemicals in environment which causes health hazards (Akoto et al., 2014) and also induces resistance in target pathogens (Bosch et al., 2014). These issues exert pressure to initiate alternative strategy to decrease dependence on pesticides in crop protection (Rai and Ingle, 2012). Biopesticide application has not been much exploited and still in rudiment owing to available fewer commercial formulations. Nonetheless, in few studies, maize disease management through bio-pesticide has been recommended concomitantly with synthetic fungicides. However, bio-pesticide exhibits highly variable results due to variability in environmental conditions. Hence, there is a pressing need to explore more stable approaches of ecofriendly antimicrobial compounds to combat future challenges of phytopathogens (Saharan et al., 2014).

Available immense sources of biomaterials can be researched and utilized in modulated way in plant disease control. Functionalized biomaterial based formulation would work in multi-dimensional mode to strengthen the plant defense system along with antimicrobial activity (Liu et al., 2007; Chen et al., 2014; Sathiyabama and Manikandan, 2016). Many biomaterials have been isolated from plants and other living organisms and evaluated for plant disease management. Amongst these biomaterials, chitosan earned more emphasis because of biodegradable, bioactive functional groups, strong adhering property to biological membrane and strong elicitors for plants (Prashanth and Tharanathan, 2007; Kean and Thanou, 2010; Rodriguez et al., 2011). Chitosan has been researched noticeably in agricultural field for growth, development and protection (Hadwiger, 2013). Molecular nanobiotechnology enables customized molecule-to-molecule arrangement which display novel and more efficient bioactivities (Rai and Ingle, 2012). In agricultural field, utilization of chitosan based nano materials especially for growth, development and protection is rare as compared to bulk chitosan. Chitosan based nanomaterials clutch enormous promises regarding their application in plant protection and growth (Shukla et al., 2013). Available literature on chitosan based nanomaterials raveled the variability in size, stability and other bio-chemical characteristics which affect their bioactivity. This is commonly due to variability in molecular weight, polymerization, degree of deacetylation of chitosan and applied methods (Huang et al., 2009). Hence, plenty of scope exists to improve the various characters of chitosan nanomaterials through modifications to render higher and novel bioactivities (Saharan et al., 2013; Saharan et al., 2015). Besides many efforts to control maize diseases by chemical means and bio-pesticide application, stalk rots continue to be a serious problem in most of the commercially grown cultivars (Kaur et al., 2012; Thori et al., 2012; Khokhar et al., 2014). 


\section{Materials and Methods}

\section{Materials}

Laboratory synthesized Cu-chitosan nanocomposites as described earlier (Saharan et al., 2013; Saharan et al., 2015) were used. The seed lots (Surya local variety) used during the course of research were selected carefully by visual assessment to ensure the disease free and healthy vigour seeds. Highly infectious Fusarium verticillioides causing PFSR disease of maize were procured from All Indian Co-ordinated Research Project on Maize, Department of Plant Pathology, RCA, MPUAT, Udaipur.

\section{Antifungal activity of Cu-chitosan NCPs} against PFSR disease in pot condition

Seeds of Surya local variety were treated with $\mathrm{Cu}$-chitosan NCPs as $(0.02,0.06,0.1$, and $0.14 \%$ w/v) along with control (without treatment), bulk chitosan and commercial fungicide in aqueous suspension for 4 and 8 hrs. Treated seeds were sown in earthen pots filled with standard potting soil obtained from field and kept in net house in natural environment. Inoculum of $F$. verticillioids was added in the pot soil before sowing. Foliar spray treatments of $\mathrm{Cu}$-chitosan NCPs (until run-off) were applied at 45 and 65 days.

\section{Antifungal activity of Cu-chitosan NCPs PFSR disease in field condition}

Seeds of Surya local variety (4 and $8 \mathrm{hrs}$ seed treatment) were sown in field in randomized block design (RBD). The test field was maintained as per standard agronomic and plant protection management.

Most effective four treatments of $\mathrm{Cu}$-chitosan NCPs were selected from pot experiments and applied in field as foliar spray at 45 and 65 days from sowing. Active culture of $F$. verticillioides was used as suspension in aqueous and inoculated at flowering stage by using toothpick method of inoculation (Young; 1943; Singh and Kaiser, 1989; Desai and Hegde, 1992). For this, first an oblique hole about 1.5-2.0 $\mathrm{mm}$ was made in the second or third internode of the stalk from the ground level with the help of a zebber and the toothpick was inserted in the hole. Artificial inoculation was performed using toothpick inoculation as well as on already developed sick plot.

\section{Disease assessment}

The observations for assessment of disease severity in pot experiments and field experiments were recorded. At the time of maturity, lower internodes of these plants were split longitudinally to see the extent of pith damage.

Disease severity was recorded on 1 to 9 standard disease rating scale (Table 1 and Fig. 1) as described (Young, 1943; Payak and Sharma, 1983; Singh and Kaiser, 1989; Desai and Hegde, 1992; Sobowale, 2011). Further, the disease severity and per cent efficacy of disease control (PEDC) was calculated by using following formula given by Chester (1959) and Wheeler (1969).

$$
\begin{aligned}
& \text { Disease severity }=\frac{\text { Sum of all individual disease rating }}{\text { Total number of leaf assessed } x \text { Maximum rating }} \times 100 \\
& \text { PEDC }=\frac{\text { Infection index in control }- \text { Infection index in treatment }}{\text { Infection index in control }} \times 100
\end{aligned}
$$




\section{Statistical analysis}

Plot means were subjected to analysis of experimental designs. The statistical analysis were used as post hoc test to determine the significance difference between the treatments at $\mathrm{P}=0.05$ level. The analysis was performed with JMP software version 12 (SAS, 2010) using Turkey Kramer HSD test. Each experiment was repeated twice for consistency of results and each treatment was consisting of minimum three replicates.

\section{Result and Discussion}

\section{Antifungal activity of Cu-chitosan NCPs against PFSR disease in pot condition}

In Surya local variety with $4 \mathrm{hrs}$ of seed treatment and two foliar sprays, control plant (water treated + inoculation) showed average disease severity $47.8 \%$. All plants treated with 0.02 to $0.14 \%$ Cu-chitosan NCPs showed significant antifungal activity, express lower disease severity $29.5 \%$ to $24.7 \%$. Commercial fungicides bavistin $(1 \%)$ and bulk chitosan $(0.01 \%)$ were used as positive control, showed $28.8 \%$ and $33.2 \%$ disease severity respectively. PEDC was found maximum $(48.1 \%)$ at $0.1 \%$ of $\mathrm{Cu}$-chitosan NCP. At statistical level significantly higher PEDC value was observed in $0.1 \%$ of $\mathrm{Cu}-$ chitosan NCP from all other treatments (Table 2; Fig. 2A).

In Surya local variety after $8 \mathrm{hrs}$ of seed treatment with two foliar sprays, control plants (water treated + inoculation) showed average disease severity $44.4 \%$. All plants treated with 0.02 to $0.14 \%$ of $\mathrm{Cu}$-chitosan NCPs showed significant antifungal activity and express lower disease severity $33.4 \%$ to $22.4 \%$. Commercial fungicides Bavistin (1 $\%)$ and bulk chitosan $(0.01 \%)$ were used as positive control, showed $21.4 \%$ and $44.4 \%$ disease severity respectively. PEDC was found maximum (49.6\%) at $0.1 \%$ and 0.14 $\%$ of Cu-chitosan NCP. At statistical level 0.1 $\%$ and $0.14 \%$ of $\mathrm{Cu}$-chitosan NCPs and fungicide were found significantly higher from all other treatments (Table 3; Fig. 2B).

\section{Antifungal activity of Cu-chitosan NCPs against PFSR disease in field condition}

In Surya local variety (4 hrs treated seed), control plants (water treated + inoculation) showed average disease severity $58.3 \%$. All plants treated with 0.02 to $0.14 \% \mathrm{Cu}$ chitosan nanocomposites showed significant antifungal activity and express lower disease severity $30.6 \%$ to $44.6 \%$. Bulk chitosan, commercial fungicide bavistin $(1 \%)$ and $\mathrm{CuSO}_{4}$ were used as positive control, showed $44.8 \%$, $50.3 \%$ and $52.8 \%$ disease severity respectively. PEDC was found maximum $(33.9 \%)$ at $0.06 \%$ of Cu-chitosan NCP (Table 4).

In Surya local variety ( $8 \mathrm{hrs}$ treated seed), control plants (water treated + inoculation) showed average disease severity $35.4 \%$. All plants treated with 0.02 to $0.14 \% \mathrm{Cu}$-chitosan NCPs showed significant antifungal activity and express lower disease severity $29.7 \%$ to $34.4 \%$. Bulk chitosan, commercial fungicide Bavistin (1\%) and $\mathrm{CuSO}_{4}$ were used as positive control, showed $33.8 \%, 34.9 \%$ and $33.3 \%$ disease severity respectively. PEDC was found maximum $(15.8 \%)$ at $0.06 \%$ of Cu-chitosan NCP (Table 5).

On the basis of published reports it has been revealed that nanochitosan has higher antifungal activity compared to bulk chitosan. Nanochitosan organized in nano sized and with nano size it can pass through easily to fungal and bacterial outer membranes. It has also been pointed out that higher positive charged nanochitosan has high affinity towards lipids of membranes and make transient holes. 
Table.1 Rating scale for PFSR disease

\section{Description}

Brownish and blackish discolouration only at the point of inoculation

$<25 \%$ of the inoculated internode discoloured

25 to $<50 \%$ of the inoculated internode discoloured

50 to $<100 \%$ of the inoculated internode discoloured

Total of inoculated internodediscoloured and $25 \%$ of

adjacent internode discoloured

$1 / 2$ discolouration of the adjacent internode

Discolouration of three internodes

Discolouration of four internodes

Discolouration of five internodes or plants

prematurely killed

\section{Disease rating}

1

2

3

4

5

6

7

8

9

Table.2 Effect of $\mathrm{Cu}$-chitosan nanocomposites on control of PFSR disease of maize variety (Surya local) in pots after 4 hrs of seed treatment (Data recorded at the end of physiological maturity)

\begin{tabular}{lll}
\hline Treatment & Disease severity $(\%)^{\mathrm{A}}$ & PEDC $(\%)^{\mathrm{A}}$ \\
\hline Control $^{\mathrm{B}}$ & $47.8 \pm 0.00 \mathrm{a}$ & $0.0 \pm 0.0 \mathrm{f}$ \\
Bulk chitosan $^{\mathrm{C}}$ & $33.2 \pm 0.17 \mathrm{~b}$ & $30.6 \pm 0.35 \mathrm{e}$ \\
Fungicide $^{\mathrm{D}}$ & $28.8 \pm 0.16 \mathrm{~cd}$ & $39.9 \pm 0.35 \mathrm{~cd}$ \\
Cu-chitosan NCPs & & \\
$0.02 \%$ & $29.5 \pm 0.50 \mathrm{c}$ & $38.2 \pm 1.05 \mathrm{~d}$ \\
$0.06 \%$ & $27.6 \pm 0.11 \mathrm{de}$ & $42.1 \pm 0.23 \mathrm{bc}$ \\
$0.1 \%$ & $24.7 \pm 0.22 \mathrm{f}$ & $48.1 \pm 0.47 \mathrm{a}$ \\
$0.14 \%$ & $26.6 \pm 0.05 \mathrm{e}$ & $44.3 \pm 0.12 \mathrm{~b}$ \\
\hline
\end{tabular}

${ }^{\mathrm{A}}$ Each value is mean of 3 replicates from 2 experiments. Mean \pm SE followed by same letter in column of each treatment are not significant different at $\mathrm{p}=0.05$ by Tukey - Kramer HSD,${ }^{\mathrm{B}}$ Control with water. ${ }^{\mathrm{C}}$ Chitosan dissolved in $0.1 \%$ acetic acid. ${ }^{\mathrm{D}}$ For the positive control, Bavistin $(1 \%)$ was used. PEDC $=$ Percentage efficacy of disease control was calculated compare to control

Table.3 Effect of $\mathrm{Cu}$-chitosan nanocomposites on control of PFSR disease of maize variety (Surya local) in pots after $8 \mathrm{hrs}$ of seed treatment (Data recorded at the end of physiological maturity)

\begin{tabular}{lll}
\hline Treatment & Disease severity $(\%)^{\mathrm{A}}$ & PEDC $(\%)^{\mathrm{A}}$ \\
\hline Control $^{\mathrm{B}}$ & $44.4 \pm 0.00 \mathrm{a}$ & $0.0 \pm 0.0 \mathrm{c}$ \\
Bulk chitosan $^{\mathrm{C}}$ & $44.4 \pm 0.00 \mathrm{a}$ & $0.0 \pm 0.0 \mathrm{c}$ \\
Fungicide $^{\mathrm{D}}$ & $21.9 \pm 0.33 \mathrm{c}$ & $50.8 \pm 0.75 \mathrm{a}$ \\
Cu-chitosan NCPs & & \\
$0.02 \%$ & $33.4 \pm 0.11 \mathrm{~b}$ & $24.8 \pm 0.25 \mathrm{~b}$ \\
$0.06 \%$ & $33.4 \pm 0.11 \mathrm{~b}$ & $24.8 \pm 0.25 \mathrm{~b}$ \\
$0.1 \%$ & $22.4 \pm 0.16 \mathrm{c}$ & $49.6 \pm 0.37 \mathrm{a}$ \\
$0.14 \%$ & $22.4 \pm 0.16 \mathrm{c}$ & $49.6 \pm 0.37 \mathrm{a}$ \\
\hline
\end{tabular}

${ }^{\mathrm{A}}$ Each value is mean of 3 replicates from 2 experiments. Mean \pm SE followed by same letter in column of each treatment are not significant different at $p=0.05$ by Tukey - Kramer HSD, ${ }^{\mathrm{B}}$ Control with water. ${ }^{\mathrm{C}}$ Chitosan dissolved in $0.1 \%$ acetic acid. ${ }^{\mathrm{D}}$ For the positive control, Bavistin $(1 \%)$ was used. PEDC $=$ Percentage efficacy of disease control was calculated compare to control 
Table.4 Effect of Cu-chitosan nanocomposites on control of PFSR disease of maize variety (Surya local) after 4 hrs treatment in field condition (Data recorded at the end of physiological maturity)

\begin{tabular}{lll}
\hline Treatment & Disease severity $(\%)^{\mathrm{A}}$ & PEDC $(\%)^{\mathrm{A}}$ \\
Control $^{\mathrm{B}}$ & $58.3 \pm 0.00 \mathrm{a}$ & $0.0 \pm 0.0 \mathrm{~g}$ \\
Bulk chitosan $^{\mathrm{C}}$ & $44.8 \pm 0.31 \mathrm{~d}$ & $23.1 \pm 0.54 \mathrm{~d}$ \\
Fungicide $^{\mathrm{D}}$ & $50.3 \pm 0.01 \mathrm{c}$ & $13.8 \pm 0.02 \mathrm{e}$ \\
Cu chitosan NCPs & & \\
$0.02 \%$ & $41.7 \pm 0.15 \mathrm{f}$ & $28.5 \pm 0.25 \mathrm{~b}$ \\
$0.06 \%$ & $30.6 \pm 0.01 \mathrm{~g}$ & $33.9 \pm 0.01 \mathrm{a}$ \\
$0.1 \%$ & $42.8 \pm 0.25 \mathrm{e}$ & $26.6 \pm 0.43 \mathrm{c}$ \\
$0.14 \%$ & $44.6 \pm 0.08 \mathrm{~d}$ & $23.5 \pm 0.14 \mathrm{~d}$ \\
\hline
\end{tabular}

${ }^{\mathrm{A}}$ Each value is mean of 3 replicates from 2 experiments. Mean \pm SE followed by same letter in column of each treatment are not significant different at $\mathrm{p}=0.05$ by Tukey - Kramer HSD, ${ }^{\mathrm{B}}$ Control with water. ${ }^{\mathrm{C}}$ Chitosan dissolved in $0.1 \%$ acetic acid. ${ }^{\mathrm{D}}$ For the positive control, Bavistin $(1 \%)$ was used. ${ }^{\mathrm{E}} \mathrm{CuSO}_{4}$ dissolved in water. $\mathrm{PEDC}=$ Percentage efficacy of disease control was calculated compare to control

Table.5 Effect of Cu-chitosan nanocomposites on control of PFSR disease of maize variety (Surya local) after $8 \mathrm{hrs}$ treatment in field condition (Data recorded at the end of physiological maturity)

\begin{tabular}{lll}
\hline Treatment & Disease severity $(\%)^{\mathrm{A}}$ & PEDC $(\%)^{\mathrm{A}}$ \\
\hline Control $^{\mathrm{B}}$ & $35.4 \pm 0.00 \mathrm{a}$ & $0.0 \pm 0.0 \mathrm{e}$ \\
Bulk chitosan $^{\mathrm{C}}$ & $33.8 \pm 0.05 \mathrm{c}$ & $4.30 \pm 0.15 \mathrm{c}$ \\
Fungicide $^{\mathrm{D}}$ & $34.9 \pm 0.00 \mathrm{ab}$ & $1.13 \pm 0.00 \mathrm{de}$ \\
Cu chitosan NCPs & & \\
$0.02 \%$ & $32.7 \pm 0.06 \mathrm{~d}$ & $7.46 \pm 0.17 \mathrm{~b}$ \\
$0.06 \%$ & $29.7 \pm 0.22 \mathrm{e}$ & $15.8 \pm 0.63 \mathrm{a}$ \\
$0.1 \%$ & $34.4 \pm 0.10 \mathrm{~b}$ & $2.55 \pm 0.29 \mathrm{~d}$ \\
$0.4 \%$ & $33.6 \pm 0.01 \mathrm{c}$ & $4.94 \pm 0.02 \mathrm{c}$ \\
\hline
\end{tabular}

${ }^{\mathrm{A}}$ Each value is mean of 3 replicates from 2 experiments. Mean $\pm \mathrm{SE}$ followed by same letter in column of each treatment are not significant different at $p=0.05$ by Tukey - Kramer HSD,${ }^{\mathrm{B}}$ Control with water. ${ }^{\mathrm{C}}$ Chitosan dissolved in $0.1 \%$ acetic acid. ${ }^{\mathrm{D}}$ For the positive control, Bavistin $(1 \%)$ was used. ${ }^{\mathrm{E}} \mathrm{CuSO}_{4}$ dissolved in water. PEDC $=$ Percentage efficacy of disease control was calculated compare to control

Fig.1 Scale 1-9 for PFSR disease

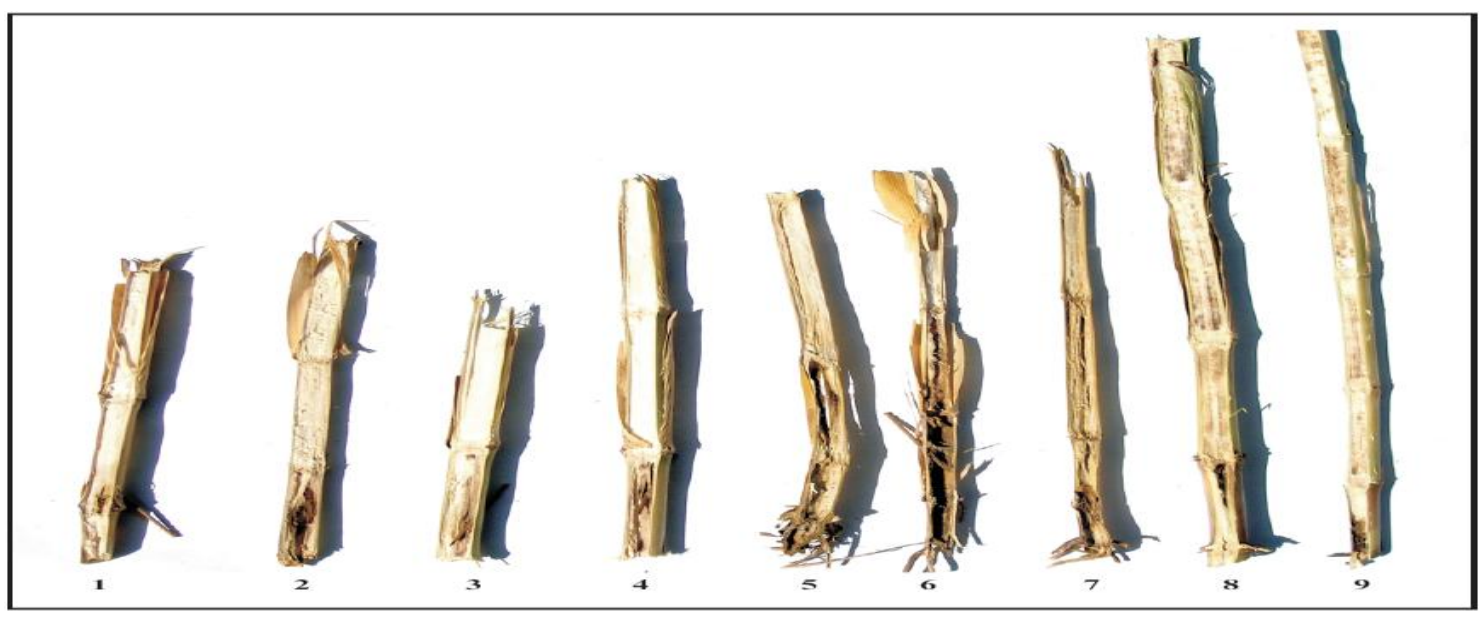


Fig.2 Disease assessment for PFSR disease in pot growing Maize plants (A) Surya local after 4 hrs and (B) 8 hrs of seed treatment
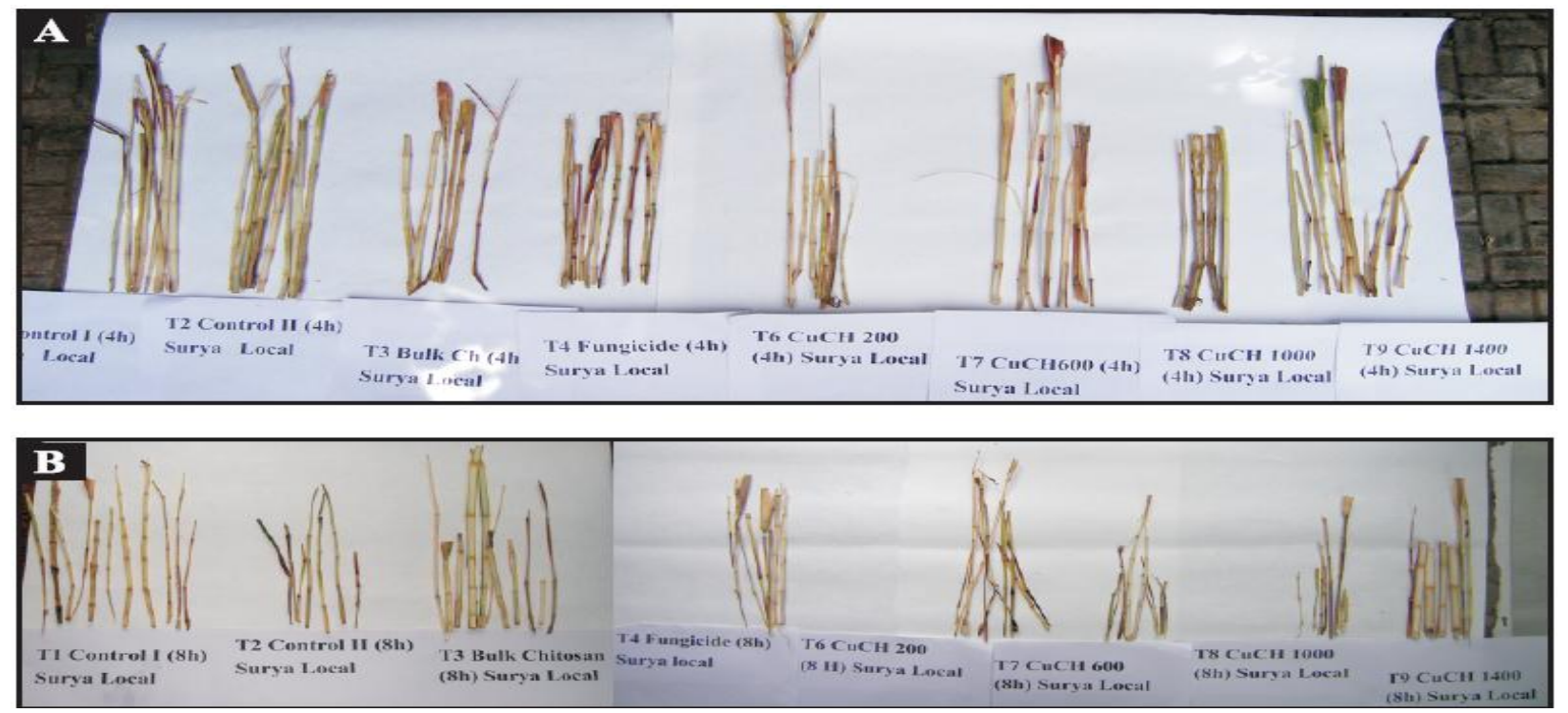

With the high surface area of nanochitosan, more and more interaction of nanoparticles could be happened on external and internal surfaces of fungi and bacteria which lead to inhibition of various metabolic reactions. On the other hand, chitosan in nanoform also act strong binder of metals in the cell wall of fungi and bacteria (Qi et al., 2004; Du et al., 2009; Saharan et al., 2013; Saharan et al., 2015).

In pot experiments, it is proved that $\mathrm{Cu}$-chitosan NCPs expressed strong antifungal activity against $F$. verticillioides, causing PFSR disease in maize. In Surya local after 4 hrs of seed treatment PEDC was found maximum (48.1\%) at $0.1 \%$ concentration of $\mathrm{Cu}$-chitosan NCP. In Surya local after $8 \mathrm{hrs}$ of seed treatment PEDC was found maximum (49.6\%) in both $0.1 \%$ and $0.14 \%$ concentration of $\mathrm{Cu}$-chitosan NCP. Overall in present study, $\mathrm{Cu}$-chitosan NCPs at the concentration of $0.1 \%$ and $0.14 \%$ found effective in controlling PFSR in pot experiments. These results are competitive with earlier reports where $\mathrm{Cu}$-chitosan $\mathrm{NCPs}$ were found to be effective in disease control at $0.12 \%$ of Cu-chitosan nanoparticles (Saharan et al., 2015).
In field experiments, it is proved that $\mathrm{Cu}$ chitosan NCPs expressed strong antifungal activity against $F$. verticillioides, causing PFSR disease in maize. In both treatments 4 and $8 \mathrm{hrs}$ of Surya local PEDC was found maximum (33.9 and $15.8 \%$ ) at $0.06 \%$ concentration of $\mathrm{Cu}-$ chitosan NCP. Overall in present study, $\mathrm{Cu}-$ chitosan NCPs at the concentration of $0.06 \%$, $0.1 \%$ and $0.14 \%$ found effective in controlling PFSR in field experiments. From our study it is evident that Cu-chitosan NCPs have remarkable potential at field towards crop protection. Thus, the use of natural chitosan can be replaced by $\mathrm{Cu}$-chitosan NCPs for prospective disease management in plants. Previous results revealed that chitosan compounds are clearly recognized by the surfaces of leaves. No exploitation of this type of work has been reported previously.

In conclusion, overall in present study, $\mathrm{Cu}$ chitosan NCPs has established as very effective antifungal agent against PFSR of maize in pot condition as well as at field condition. All together Cu-chitosan NCPs have remarkable potential in field conditions for crop protection. Therefore, our study claimed that $\mathrm{Cu}$-chitosan NCPs could be a new resourceful antipathogenic agent for sustainable agriculture. 


\section{Acknowledgements}

The authors wish to acknowledge Department of Science and Technology, Government of Rajasthan, Jaipur for their support in research work on Nano-chitosan in plant protection.

\section{References}

Akoto, O., Bismark Eshun, F., Darko, G. and Adei, E. 2014. Concentrations and health risk assessments of heavy metals in fish from the Fosu Lagoon. Int. J. Environ. Res., 8(2): 403-410.

Anonymous. 2015(a). Directorate of economics and statistics, Department of agriculture and cooperation, Ministry of Agriculture, Government of India.

Anonymous. 2015(b). Vital Agriculture Statistics, Statistical cell, Directorate of Agriculture, Pant krishi Bhawan, Jaipur pp47.

Bosch, F.V., Oliver, R., Berg, F.V., Paveley, N. 2014. Governing principles can guide fungicide-resistance management tactics. Annual Rev. Phytopathol., 52: 175-195.

Cassman, K.G., Dobermann, A., Walters, D.T. and Yang, H. 2003. Meeting cereal demand while protecting natural resources and improving environmental quality. Annual Rev. Environ. Res., 28: 315-358.

Cassman, K.G. and Liska, A.J. 2007. Food and fuel for all: realistic or foolish? Biofuels, bioproducts and biorefining, 1(1): 18-23.

Chen, J., Zou, X., Liu, Q., Wang, F., Feng, W. and Wan, W. 2014. Combination effect of chitosan and methyl jasmonate on controlling Alternaria alternata and enhancing activity of cherry tomato fruit defense mechanisms. Crop Protection, 56: 31-36.

Chester, K.S. 1959. How sick is the plant? In: Plant Pathology an Advances Traits (Eds.J.G.Horsfall and A.E. Diamond), Academic Press, New York. 1: 199-242.

Du, W.L., Niu, S.S., Xu, Y.L., Xu, Z.R. and Fan, C.L. 2009. Antibacterial activity of chitosan tripolyphosphate nanoparticles loaded with various metal ions. Carbohydrate polymers, 75: 385-389.

Desai, S. and Hegde, K.K. 1992. Identification of suitable method and time for artificial inoculation of maize with stalk rotting fungi. Indian Phytopathol., 45(3): 381382.

Grassini P., Thorburn J., Burr C. and Cassman K.D. 2011. High-yield irrigated maize in the Western US Corn Belt: I. On-farm yield, yield potential, and the impact of agronomic practices. Field Crops Res., 120: $142-150$.

Hadwiger, L.A. 2013. Multiple effects of chitosan on plant systems: Solid science or hype. Plant Sci., 208: 42-49.

Huang, K.S., Sheu, Y.R. and Chao, I.C. 2009. Preparation and properties of nanochitosan. Polymer-Plastics Technol. Engi., 48: 1239-1243.

Khokhar, M.K., Sharma, S.S. and Gupta, R. 2014. Influence of sowing dates on incidence and severity of post flowering stalk rot of Maize caused by Fusarium verticillioides. J. Mycol. Plant Pathol., 44(2): 205-208.

Kaur, A., Bedi, S., Gill, G.K. and Kumar, M. 2012. Effect of nitrogen fertilizers on radiation use efficiency, crop growth and yield in some maize (Zea mays L) genotypes. Maydica Electronic Publication, 57: 75-82.

Liu, J., Tian, S.P., Meng, X.H., and Xu, Y. 2007. Control effects of chitosan on postharvest diseases and physiological response of tomato fruit. Postharvest Biol. Technol., 44: 300-306.

Payak, M.M. and Sharma, R.C. 1980. An inventory and bibliography for diseases in India. Division of Mycology and Plant Pathology, IARI, New Delhi.

Prashanth, K.V.H. and Tharanathan, R.N. 2007. Chitin/chitosan: modifications and their unlimited application potential- an overview. Trends in Food Sci. Technol., 18: 117-131.

Qi, L., Xu, Z., Jiang, X., Hu, C. and Zou, X. 2004. Preparation and antibacterial activity of chitosan nanoparticles. 
Carbohydrate Res., 339(16): 2693-2700.

Rai, M. and Ingle, A. 2012. Role of nanotechnology in agriculture with special reference to management of insect pests. Appl. Microbiol. Biotechnol., 94: 287-293.

Rathore, R.S., Bohra, B., Trivedi, A. and Mathur, K. 2005. An overview of fusarium stalk rot of maize in Rajasthan: Progress and future perspective, In: proceedings of $9^{\text {th }}$ asian regional maize workshop, CAAS and CIMMYT, Beijing, China, pp. 175-178.

Rodriguez, A.B.F., Costales, D., Cabrera, J.C. and Téllez, M.A.M. 2011. Chitosan physic-chemical properties modulate defense responses and resistance in tobacco plants against the oomycete Phytophthora nicotianae. Pesticide Biochemistry and Physiol., 100: 221-228.

Saharan, V., Sharma, G., Yadav, M., Choudhary, M. K., Sharma, S.S., Pal, A., Raliya, R. and Biswas, P. 2015. Synthesis and in vitro antifungal efficacy of $\mathrm{Cu}-$ chitosan nanoparticles against pathogenic fungi of tomato. Int. J. Biol. Macromol., 75: 346-353.

Saharan, V., Khatik, R., Choudhary, M.K., Mehrotra, A., Jakhar, S., Raliya, R., Nallamuthu, I.and Pal, A. 2014. Nanomaterials for plant protection with special reference to Nano chitosan, In: proceedings of $4^{\text {th }}$ Annual International conference on Advances in Biotechnology, GSTF, Dubai, pp 23-25.

Saharan, V., Mehrotra, A., Khatik, R., Rawal, P., Sharma, S.S. and Pal, A. 2013.
Synthesis of chitosan based nanoparticles and their in vitro evaluation against phytopathogenic fungi. Int. J. Biol. Macromolecules, 62: 677-683.

SAS. 2010. JMP: User's Guide, Version 12. SAS Institute, Inc., Cary, NC, USA.

Shekhar, M., Kumar, S., Sharma, R.C. and Singh, R. 2010. Sources of resistance against post-flowering stalk rots of maize. Arch. Phytopathol. Plant Protection, 43(3): 259-263.

Shukla, S.K., Mishra, A.K., Arotiba, O.A. and Mamba, B.B. 2013. Chitosan-based nanomaterials: A state-of-the-art review. Int. J. Biol. Macromolecules, 59: 46-58.

Singh, R.D.N. and Kaiser, K.M. 1989. Evaluation of different field inoculation techniques to induce charcoal rot of maize. Environ. Ecol., 7(3): 697-700.

Sobowale, A.A. 2011. Determination of infective, non-lethal dosage of Fusarium verticillioides in maize (Zea mays) stem and effective inoculation method in the screenhouse. J. Agri. Biol. Sci., 2(5): 118122.

Thori, H.R., Bunker, R.N., Mathur, K. and Sharma, S.S. 2012. Integrated management of post flowering stalk rot of maize caused by Fusarium moniliforme. Indian Phytopathol., 65(2): 151-154.

Wheeler, B.E.J. 1969. An Introduction to plant disease. John Wiley and Sons Limited, London, pp 301.

Young, H.C. 1943. The toothpick method of inoculating corn for ear and stalk rots. Phytopathol., 33: 16.

\section{How to cite this article:}

Manju Kumari Choudhary, Arunabh Joshi, S.S. Sharma and Vinod Saharan. 2017. Effect of Laboratory Synthesized Cu-Chitosan Nanocomposites on Control of PFSR Disease of Maize caused by Fusarium verticillioids. Int.J.Curr.Microbiol.App.Sci. 6(8): 1656-1664. doi: https://doi.org/10.20546/ijcmas.2017.608.199 